\title{
Comparison of J-Shaped Incision and Mercedes Incision for Liver Transplantation
}

\begin{abstract}
Wound-related and incision-related complications such as wound infections and incisional hemias are common after liver transplantation. Advances in surgic al, a nesthesiological, critical care, and immunological innovations have led to a dramatic reduction in postoperative morbidity and mortality. Orthotopic liver transplant (OLT) has been first described with traditionally Mercedes type incision. Less traumatic J shaped incision has been used more frequently. We analyzed retrospectively 110 consec utive patients submitted to OLT in our institution from November 2010 to December 2012. In our program, beginning on September 2011, orthotopic liver transplantation (OLT) was performed using J-shaped $(J)$ incision routinely, switching from a previous Mercedes (M) incision. We compared the incidence for surgic al site infection (SSI), inc isiona Ihemia , a nd overall sa tisfaction. Fifty patients submitted to OLT using J -shaped incision were compared to 60 patients with $M$ incision. Age, sex distribution, indication for OLT, and MELD score were similar in both groups. Three patients in the $\mathrm{J}$ group developed SSI, $6 \%$, while $13,21.6 \%$, patients in the M group developed SSI $(p=0.02)$. Incisional hemia was observed in 9 patients in the J group, $18 \%$, compared with 22 patients in M group, 36.6\% ( $p=0.03)$. Regarding overall satisfaction with the results of the incision, 48 patients, $96 \%$, in J group gave the highest score, while in the $M$ group, 45 patients, $75 \%$, attributed the highest score for the questionnaire. After we have decided to switch from Mercedes type incision to J-shaped incision, OLT was feasible in all patients. When refraining to incise rectus abdominis on both sides, we provide a less traumatic incision, which leads to fewer complic ations postoperatively. Our results suggest that a J-shaped incision is preferred to other inc isions for OLT.
\end{abstract}

\section{Introduction}

Liver transplantation has become the treatment of choice for patients with end-stage liver disease. Advances in surgical, anesthesiological, critical care, and immunological innovations have led to a dramatic reduction in postoperative morbidity and mortality. Wound-related and incision-related complications such as wound infections and incisional hernias are common after liver transplantation and they imply considerable in morbidity and also in mortality [1-6].

In recent years, liver transplantation increased exponentially in Brazil, and this is expected to continue the growth progressively [7]. The cost of liver transplantation with living donor is superior to deceased donor transplantation. The most expensive item in liver transplantation, bothdeceased donor and living donor, is the medications [8].

Even the best tests, drugs and treatments can't decrease complications even when a flawless surgical technique is performed [9]. Liver transplants have considerable rates of surgical site infection $(20,7 \%)$. These patients are hospitalized on average 15 days, allowing greater colonization and increasing the risk of this complication [10].

The success of liver transplantation is when the patient is able to re-enter the job market as early as possible [11]. Nutritional therapy

\section{Journal of Surgery}

Julio Cesar Wiederkehr*, Mauro Rafael Igreja, Nelson Gonçalves, Amanda Pereira Sequinel, Ana Luiza Komniski Sampaio, Gabrielle Paggi Montemezzo, Henrique Wiederkehr, Matheus Pedro Wasemand Barbara Wiederkehr

Department of Transplant Surgery, Hospital Santa Isabel, Blumenau, Brazil

*Address for Correspondence

Julio Cesar Wiederkehr, Department of Transplant Surgery, Hospital Santa Isabel, Av Visconde de Guarapuava, 4663, ap 101. 80240-010 Curitiba, PR, Brazil, E-mail: julio.wieder@gmail.com

Copyright: (๑) 2015 Wiederkehr JC, et al. This is an open access article distributed under the Creative Commons Attribution License, which permits unrestricted use, distribution, and reproduction in any medium, provided the original work is properly cited.

Submission: 09 January 2015

Accepted: 18 March 2015

Published: 23 March 2015

Reviewed \& Approved by: Dr. Waldo Concepcion, Professor, Department of Surgery, Stanford University School of Medicine, USA

is also effective in improving the prognosis and quality of life of transplanted patients [12].

Also, patients undergoing orthotopic liver transplantation (OLT) show a high risk of developing an incisional hernia [13]. Several factors as length and type of wound incision, jaundice, wound infection, nutritional status of the patient (obesity or malnutrition), and steroid therapy have been involved in the development of incisional hernia after OLT [14].

In order to gain full access to the liver during OLT, an extensive incision is usually required. The incisions commonly used are Mercedez, J shaped and midline. The Mercedez incision is a transverse incision with median extension, both on the rectus abdominis muscle. The midline incision includes solution of continuity from the xiphoid process to the umbilicus, in the sagittal plane. Finally, $\mathrm{J}$-shaped is performed by unilateral subcostal incision with extending median [15].

The Mercedez and all other incisionsaresignificantly associated with incisional hernias in older patients with higher BMI (Body Mass Index), diabetes mellitus and longer admission in ICU (Intensive Care Unit) and hospital [16].

In this present report we compare the traditional Mercedes type with a J-shaped incision in adults patients submitted to OLT in our institution.

\section{Material and Method}

We retrospectively analyzed 110 consecutive patients, with more than six-month of follow-up, submitted to OLT between November 2010 and December 2012. In our program, beginning on September 2011, orthotopic liver transplantation (OLT) was performed using $\mathrm{J}$-shaped (J) incision routinely, switching from a previous Mercedes (M) incision. The same team performed all procedures. The Mercedes incision includes bilateral subcostal transverse incision with a midline extension, incising both rectus abdominis muscles. The J-shaped incision consists of a midline incision with a right transverse incision, only compromising the right rectus abdominis muscle. In both types of incision, the same subcostal retractor was used. In all 
Citation: Wiederkehr JC, Igreja MR, Gonçalves N, Sequinel AP, Komniski Sampaio AL, et al. Comparison of J-Shaped Incision and Mercedes Incision for Liver Transplantation. J Surgery. 2015;3(1): 3.

patients the abdominal cavity was drained with two tubular drains. The abdominal wall was closed using \#1 polydioxanone (PDS $\left.{ }^{\mathrm{m}} \mathrm{II}\right)$ running suture, and the skin with a 3-0 nylon interrupted suture. Incidence of surgical site infection (SSI), incisional hernia, and degree of satisfaction was obtained. For the latter, phone call interview was made and the patient was required to give a grade of his/her overall satisfaction, from 1 (not happy) to 5 (pleased), with the incision. Chisquare test was used for statiscal analyses.

\section{Results}

A total of 110 patients, fifty patients undergoing J-shaped incision (group J) and sixty on Mercedes incision (group M). There was no statistically significant difference between age, sex distribution, indication for OLT and MELD average (Group M = 17,07 vs Group J $=17,90)$. Regarding complications, there was a significant difference between the groups $\mathrm{J}$ and $\mathrm{M}$, as shown in Tables 1 and 2 .

Regarding overall satisfaction with the results of the incision, 48 patients, $96 \%$, in J group gave the highest score, while in the M group 45 patients, $75 \%$, attributed the highest score for the questionnaire. When asked about daily activities, the Mercedes incision group had worse grades than J-shaped group $(p=0.018)$. Assessing the need for reoperation, there was no significant difference between the two groups. At the surgery, the $\mathrm{M}$ group needed more blood components than J group as show in the Table 3.

The average time of surgery was 4 hours and 54 minutes in group $\mathrm{M}$ and 4 hours and 39 minutes in group J. The average time of ischemia was 9 hours and 3 minutes and 8 hours and 42 minutes in group J.

\section{Discussion}

In our series the incidence for incisional hernia was $28.18 \%$. Our data confirmed that eventration post liver transplantation is a surgical complication with an incidence of $8 \%$ among our cases compared with literature data that range from $4.6 \%-34 \%[13,17,18]$.
This complication was much lower when J shaped incision was used, $18 \%$ compared to $36.6 \%$ of Mercedes incision. The same reduction in incisional hernia following OLT was reported by others $[17,19]$.

In an experimental review by Biondo-Simões et al., it was shown that the procedure of hepatectomy leads to a delay of the healing process, interfering with collagen synthesis and angiogenesis, which could explain the results of incisional hernia, but not addressing type of incision [20].

Incisional hérnia repairs are common and costly. Although rarely fatal, this complication can has substantial clinical and cost implications. The prevalence of incisional hérnia after laparotomy is reported to be between $11 \%$ and $20 \%$. It causes pain and other problems, such as bowel obstruction, in carceration and strangulation. It's known that the risk is different according to the procedure and the technique [21].

It is important to find out which technique causes less insicional hernia because this is a public health problem and many researchers are seeking new methods to prevent and treat the incisional hérnia, as new compounds derived from polypropylene, polyurethane, and polydiaxone [22-24].

In a recent review of 450 consecutive OLT, Piardi et al. reported risk factor influencing the development of post OLT incisional hernia [18]. No significant difference was observed for age, OLT indication, Child-Pugh score, albumin, comorbidities, operative time, transfusions, immunosuppressant regimen, and graft rejection episodes as well as for the incisional approach and hospital stay. Gender, body mass index (BMI), preoperative ascites, and pulmonary complications after OLT were risk factors associated with the incidence of incisional hernia [18].

We also have found a lower incidence for surgical site infection in patients with J shaped incision, $6 \%$ vs $21.6 \%$. After we have decided to switch from Mercedes type incision to J-shaped incision, OLT was feasible in all patients with this incision. When refraining to

Table 1: Complications.

\begin{tabular}{|l|c|c|}
\hline Complication & Group J & Group M \\
\hline SSI & $3(6 \%)$ & $13(21.6 \%)$ \\
\hline Incisional hernia & $9(18 \%)$ & $22(36.6 \%)$ \\
\hline
\end{tabular}

'The basic cause of liver transplantation is described in the following table

Table 2: Primary disease.

\begin{tabular}{|l|c|c|}
\hline M Group & $\%$ & J Group \\
\hline Hepatitis C Cirrhosis & $34 \%$ & Hepatocellular Carcinoma \\
\hline Alcohol Cirrhosis & $16 \%$ & Hepatitis C Cirrhosis \\
\hline Hepatocellular Carcinoma & $16 \%$ & Alcohol Cirrhosis \\
\hline Hepatitis B Cirrhosis & $9 \%$ & Hepatitis B Cirrhosis \\
\hline Cryptogenic Cirrhosis & $7 \%$ & Cryptogenic Cirrhosis \\
\hline
\end{tabular}

Table 3: Average blood components need at surgery in units

\begin{tabular}{|l|c|c|c|c|c|}
\hline Group & Redcells & Plasma & Cryoprecipitate & Platelets \\
\hline M & 2.70 & 3.30 & 0.39 & 3.28 \\
\hline J & 2.12 & 1.84 & 0.58 & 217.19 \\
\hline
\end{tabular}


Citation: Wiederkehr JC, Igreja MR, Gonçalves N, Sequinel AP, Komniski Sampaio AL, et al. Comparison of J-Shaped Incision and Mercedes Incision for Liver Transplantation. J Surgery. 2015;3(1): 3.

incise rectus muscularis on both sides, we provide a less traumatic incision, which leads to fewer complications postoperatively. Despite maintaining intact one side of the abdominal wall, we have not found any difficult performing OLT in the patients of the present series.

Also when the patient was asked about the overall satisfaction regarding the incision used for OLT, a higher number of patients with J-shaped incision reported to be pleased than those with Mercedes type incision, $96 \%$ vs $75 \%$. Although a fully subjective evaluation of the patient, this reflects attending physician impression. No adaptation in the retractor or surgical technique was necessary in order to gain full access to the liver for OLT.

Recently, Demirbas et al. reported a series of 32 patients submitted to living donor right hepatectomy using upper midline incision [15] Use of this type of incision has not yet been reported in OLT.

Our results suggest that a J-shaped incision is preferred to other incisions for OLT.

There is a need for more detailed studies on the influence of the incision on the hepatectomy procedure, partial or total, because there are few reviews that explain about this.

\section{References}

1. Piazzese E, Montalti R, Beltempo P, Bertelli R, Puviani L, et al. (2004) Incidence, predisposing factors, and results of surgical treatment of incisional hernia after orthotopic liver transplantation. Transplant Proc 36: 3097-3098.

2. Donataccio M, Genco B, Donataccio D (2006) Right subcostal incision in live transplantation: prospective study of feasibility. Transplant Proc 38: 1109 1110.

3. Muller V, Lehner M, Klein P, Hohenberger W, Ott R (2003) Incisional hernia repair after orthotopic liver transplantation: a technique employing an inlay/ onlay polypropylene mesh. Langenbecks Arch Surg 388: 167-173.

4. Shi LW, Verran D, Rao AR, Stewart GJ, McCaughan GW (2003) Incisional hernia following orthotopic liver transplantation. Transplant Proc 35: 425-426.

5. Janssen H, Lange R, Erhard J, Malago M, Eigler FW, et al. (2002) Causative factors, surgical treatment and outcome of incisional hernia after liver transplantation. Br J Surg 89: 1049-1054.

6. Strong RW (2006) Living-donor liver transplantation: an overview. J Hepatobiliary Pancreat Surg 13: 370-377.

7. Ramos E, Coelho JCU (2010) Transplante hepático no Brasil: situação atual ABCD Arq Bras Cir Dig 23: 143.

8. Coelho JCU, Trubian PS, Freitas AC, Parolin MB, Schulz GJ, et al. (2005) Comparação entre o custo do transplante hepático cadavérico e o intervivos. Rev Assoc Med Bras 51: 158-163.

9. Eghtesad B, Kadry Z, Fung J (2005) Technical considerations in liver transplantation: what a hepatologist needs to know (and every surgeon should practice). Liver Transpl 11: 861-871.

10. Oliveira AC, Braz NJ, Ribeiro MM (2007) Incidência da infecção do sitio cirúrgico em um hospital universitário. Cienc Cuid Saude 6: 486-493.

11. Parolin MB, Coelho JC, Costa PB, Pimentel SK, Santos-Neto LE, et al. (2001) Retorno ao trabalho de pacientes adultos submetidos a transplante de fígado. Arq Gastroenterol 38: 172-175.

12. Parolin MB, Zaina FE, Lopes RW (2002) Terapia nutricional no transplante hepático. Arq Gastroenterol 39: 114-122.

13. Kahn J, Müller H, Iberer F, Kniepeiss D, Duller D, et al. (2007) Incisional hernia following liver transplantation: incidence and predisposing factors. Clin Transplant 21: 423-426

14. Gómez R, Hidalgo M, Marques E, Marin L, Loinaz C, et al. (2002) Incidence and predisposing factors for incisional hernia in patients with liver transplantation. Hernia 5: 172-176

15. Demirbas M, Bulutcu F, Dayangac M, Yaprak O, Guler N, et al. (2013) Which incision is better for living-donor right hepatectomy? Midline, J-shaped, or Mercedes. Transplant Proc 45: 218-221.

16. Fikatas P, Schoening W, Lee JE, Chopra SS, Seehofer D, et al. (2013) Incidence, risk factors and management of incisional hernia in a high volume liver transplant center. Ann Transplant 18: 223-30.

17. Heisterkamp J, Marsman HA, Eker H, Metselaar HJ, Tilanus HW, et al. (2008) A J-Shaped subcostal incision reduces the incidence of abdominal wall complications in liver transplantation. Liver Transpl 14: 1655-1658.

18. Piardi T, Audet M, Panaro F, Gheza F, Cag M, et al. (2010) Incisional hernia repair after liver transplantation: role of the mesh. Transplant Proc 42: 1244 1247.

19. D'Angelica M, Maddineni S, Fong Y, Martin RC, Cohen MS, et al. (2006) Optimal abdominal incision for partial hepatectomy: increased late complications with Mercedes type incisions compared to extended right subcostal incisions. World J Surg 30: 410-418.

20. Biondo-Simões MLP, Bonato FT, Menacho AM, Drechmer M, Cavalcanti TCS, et al. (2011) Cicatrização da parede abdominal após hepatectomia parcial. Rev Col Bras Cir 38: 127-139.

21. Bensley RP, Schermerhorn ML, Hurks R, Sachs T, Boyd CA, et al. (2013) Risk of late-onset adhesions and incisional hernia repairs after surgery. J Am Coll Surg 216: 1159-1167.

22. Mavrodin CM, Pariza G, Ion D, Ciurea M (2014) The economic analysis of two treatment procedures for incisional hernias - alloplastic versus tissular. J Med Life 7: 90-93.

23. Bellón JM, Pérez-López P, Simón-Allue R, Sotomayor S, Pérez-Köhler B, et al. (2014) New suture materials for midline laparotomy closure: an experimental study. BMC Surg 14: 70

24. Nieuwenhuizen J, Eker HH, Timmermans L, Hop WC, Kleinrensink GJ, et al. (2013) A double blind randomized controlled trial comparing primary suture closure with mesh augmented closure to reduce incisional hernia incidence. BMC Surg 13: 48. 